\title{
Atypical Teratoid/Rhabdoid Tumor
}

National Cancer Institute

\section{Source}

National Cancer Institute. Atypical Teratoid/Rhabdoid Tumor. NCI Thesaurus. Code C6906.

An aggressive malignant embryonal neoplasm arising from the central nervous system. It is composed of cells with a large eccentric nucleus, prominent nucleolus, and abundant cytoplasm. Mutations of the INI1 gene or very rarely SMARCA4 (BRG1) gene are present. The vast majority of cases occur in childhood. Symptoms include lethargy, vomiting, cranial nerve palsy, headache, and hemiplegia. 